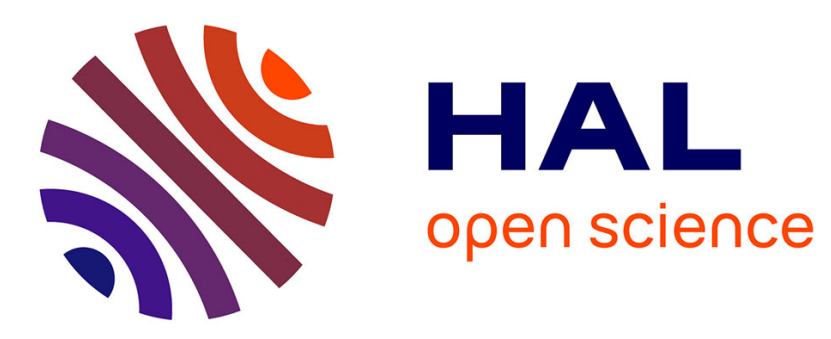

\title{
From Architectured Materials to Large-Scale Additive Manufacturing
}

\author{
Justin Dirrenberger
}

\section{To cite this version:}

Justin Dirrenberger. From Architectured Materials to Large-Scale Additive Manufacturing. Henriette Bier. Robotic Building, Springer International Publishing, pp.79-96, 2018, Springer Series in Adaptive Environments, 9783319708669. 10.1007/978-3-319-70866-9_4 . hal-01905293

\section{HAL Id: hal-01905293 \\ https://hal.science/hal-01905293}

Submitted on 20 Dec 2018

HAL is a multi-disciplinary open access archive for the deposit and dissemination of scientific research documents, whether they are published or not. The documents may come from teaching and research institutions in France or abroad, or from public or private research centers.
L'archive ouverte pluridisciplinaire HAL, est destinée au dépôt et à la diffusion de documents scientifiques de niveau recherche, publiés ou non, émanant des établissements d'enseignement et de recherche français ou étrangers, des laboratoires publics ou privés. 


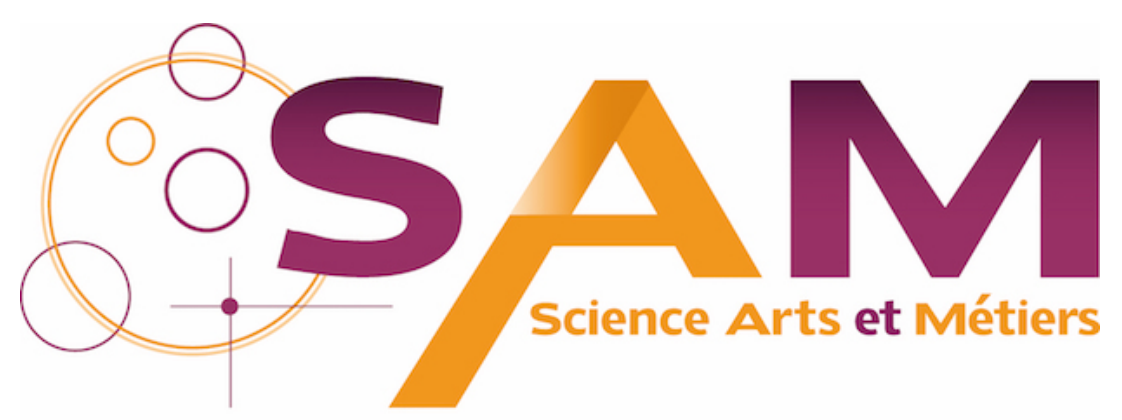

Archive Ouverte - Open Repository

\section{Science Arts \& Métiers (SAM)}

is an open access repository that collects the work of Arts et Métiers ParisTech researchers and makes it freely available over the web where possible.

This is an author-deposited version published in: https://sam.ensam.eu Handle ID: .http://hdl.handle.net/10985/13841

\section{To cite this version :}

Justin DIRRENBERGER - From Architectured Materials to Large-Scale Additive Manufacturing 2018 


\title{
From Architectured Materials to Large-Scale Additive Manufacturing
}

\author{
Justin Dirrenberger
}

\begin{abstract}
The classical material-by-design approach has been extensively perfected by materials scientists, while engineers have been optimising structures geometrically for centuries. The purpose of architectured materials is to build bridges across the microscale of materials and the macroscale of engineering structures, to put some geometry in the microstructure. This is a paradigm shift. Materials cannot be considered monolithic anymore. Any set of materials functions, even antagonistic ones, can be envisaged in the future. In this paper, we intend to demonstrate the pertinence of computation for developing architectured materials, and the not-so-incidental outcome which led us to developing large-scale additive manufacturing for architectural applications.
\end{abstract}

\section{Introduction}

Materials are ubiquitous in nature and man-made applications, from electronics to transportation or energy, but also biomedical, defence, architecture or construction. Materials have such a predominance in human existence that prehistoric periods were named after materials use (Hummel 2004). Technological progress and its impact on everyday's life are intimately linked with our capacity to control matter in the form of industrialised materials. The classical material-by-design approach has been extensively perfected by materials scientists, while civil engineers and architects have been optimising structures geometrically for centuries. The purpose of architectured materials is to build bridges across the microscale of materials and the macroscale of engineering structures, to introduce some geometry within the microstructure. This is a paradigm shift in the sense that materials cannot be considered as monolithic artefacts anymore. Any set of material functions, even antagonistic ones (Steeves et al.

J. Dirrenberger $(\square)$

Laboratoire PIMM, Arts et Métiers-ParisTech, Cnam, CNRS,

151 boulevard de l'Hôpital, 75013 Paris, France

e-mail: justin.dirrenberger@ensam.eu

J. Dirrenberger

XtreeE, 18/20 rue du Jura, CP 40502, 94623 Rungis Cedex, France 
2007), can be envisaged in the future. The development of architectured materials is intrinsically transdisciplinary, on the fringes of physics, chemistry, and mechanical engineering, but also biology, computer science, architecture, design, etc. In this work, we intend to demonstrate the pertinence of a computational approach for developing architectured materials, and the not-so-incidental outcome which led us to developing large-scale additive manufacturing for architectural applications. This paper is an extended version of a preliminary conference abstract submitted for the Next Generation Building workshop held at TU Delft in 2016 (Dirrenberger 2017).

The chapter is organised as follows: an introduction to architectured materials is given in Sect.4.2. An overview of the computational tools relevant for the development of such materials is presented in Sect.4.3. The translation of architectured materials concepts to the architectural scale corresponds to Sect.4.4. Finally, conclusions and perspectives are postponed to Sect. 4.5.

\section{Architectured Materials}

Many industrial applications require new materials with enhanced specific properties, i.e. performance per unit of mass; this is especially true for the transportation and biomedical sectors. For instance, the automotive industry, with its ever increasing requirements regarding passenger safety and fuel consumption, is an edifying example: nowadays, classical steel-based material solutions are being challenged by new lightweight aluminium alloys and advanced composites. A response from steel manufacturers was the development of advanced high-strength steels (AHSS) for yield strength designed parts in order to reduce both thickness and mass. AHSS with very high strength (1000 MPa and more) commonly exhibit poor sheet formability hence limiting the mass reduction attainable. This is especially true for martensitebased AHSS such as dual-phase (DP), complex phase (CP) and martensitic (MS) steels, depending on their martensite content. The higher the martensite content, the lower the thin-sheet formability. In order to mitigate failure and tearing of thin-sheets during deformation-based forming (stamping, blanking, etc.), a possible solution is to rely on the concept of localised heat treatment in order to soften the material where needed by locally annealing martensite, hence changing the local yield strength/ductility trade-off. Introducing such geometrical discontinuities in terms of material behaviour is characteristic of architectured materials.

Architectured materials are a rising class of materials that bring new possibilities in terms of functional properties, filling the gaps and pushing the limits of Ashby's materials performance maps (Ashby and Bréchet 2003). The term architectured materials encompasses any microstructure designed in a thoughtful fashion, such that some of its materials properties, e.g. yield strength/density, have been improved in comparison to those of its constituents, due to both structure and composite effects, which depend on the multiphase morphology, i.e. the relative topological arrangement between each phase (Ashby and Bréchet 2003; Bouaziz et al. 2008; Bréchet and Embury 2013). Localised material processing methods, such as additive 
manufacturing, or localised laser heat treatment in the case of AHSS, appear as natural candidates for developing architectured materials.

There are many examples: particulate and fibrous composites, foams, sandwich structures, woven materials, lattice structures, etc. with different objectives. For instance, developing architectured porous materials for structural, acoustic and insulation properties (Caty et al. 2008; Fallet et al. 2008), entangled monofilament of perlitic steel (Courtois et al. 2012), sandwich composite structures (Kolopp et al. 2013), segmented interlocking structures (Djumas et al. 2016), woven and non-woven textile composites (Mezeix et al. 2009; Lewandowski et al. 2012; Dirrenberger et al. 2014), crumpled metallic foils (Bouaziz et al. 2013), etc. Architectured materials have been an exciting research topic in recent years, especially regarding the processing of architectured metallic foams (Brothers and Dunand 2006; Erk et al. 2008), multiscale architectured ceramics (Mirkhalaf et al. 2014), or architectured metallic sheets (Embury and Bouaziz 2010; Chéhab et al. 2009). Apart from processing, most efforts have been focused on the modelling of architectured materials. In particular, the pioneering works done on truss-structures (Deshpande et al. 2001) and metallic foams (Deshpande and Fleck 2000) led to useful results for the modelling of architectured materials (Fleck et al. 2010). The mechanical modelling of bio-inspired architectured materials has been pursued successfully, yielding results for multi-layered materials that could be used for modelling architectured metallic sheets (Turcaud et al. 2011; Stoychev et al. 2012). Other works demonstrated the interest for designing recursive or nested material architectures to achieve enhanced specific mechanical properties (Ajdari et al. 2012; Rayneau-Kirkhope et al. 2012); finally, elastic instabilities have been considered for shape-generation of architectured materials (Bertoldi et al. 2010; Shim et al. 2013).

One can play on many parameters in order to obtain architectured materials, but all of them are related either to the microstructure or the geometry. Parameters related to the microstructure can be optimised for specific needs using a materials-by-design approach, which has been thoroughly developed by chemists, materials scientists and metallurgists. Properties improvements related to microstructural design are intrinsically linked to the synthesis and processing of materials and are therefore due to micro and nanoscale phenomena, taking place at a scale ranging from $1 \mathrm{~nm}$ to $10 \mu \mathrm{m}$. This scale is below the scope of the present chapter, in terms of topology optimisation, but has been extensively studied in the literature (Embury and Bouaziz 2010; Olson 2001; Freeman 2012).

Until now, most architectured materials in the literature have been obtained empirically. By capitalising on the concept of localised processing of thin structures, our efforts at the PIMM laboratory ${ }^{1}$ have been focused on developing systematic tools to determine materials architecturation patterns, for a given set of requirements. For instance, these patterns come as an output from a computational shape-optimisation loop developed around a heuristic generative geometry module, based on cellular automata (CA), and a cost function evaluation module, based on the finite element (FE) method. This cost function has to be minimised for given constraints (Bendsøe 
and Sigmund 2004). In the case of linear elastic problems, the cost function can be related to the elastic energy density computed by numerical homogenisation at the scale of the structure (Allaire 2002). The cost function value is then used as a feedback, and an optimised shape is generated accordingly following a specific evolution algorithm. The spatial resolution associated with the shape-optimisation can be chosen to be relevant for localised laser treatment, i.e. $1 \mathrm{~mm}$, corresponding to a representative scale of the underlying microstructure (Bironeau et al. 2016); this allows us to use homogenised behaviour for each grid-cell in the simulation (Dirrenberger 2012).

From a macroscopic viewpoint, parameters related to the geometry have mainly been the responsibility of structural and civil engineers for centuries: to efficiently distribute materials within structures. An obvious example would be the many different strategies available for building bridges. At the millimetre scale, materials can be considered as structures, i.e. one can enhance the bending stiffness of a component by modifying its geometry while keeping the lineic mass (for beams) or surfacic mass (for plates) unchanged (Weaver and Ashby 1996). On the other hand, one might need a lower flexural strength for specific applications, with the same lineic and/or surfacic masses. This can be achieved with strand structures, i.e. by creating topological interfaces in the material. Processing remains the key technological issue for further development of architectured materials, and progress is made every day in this direction at the lab scale, as it was done in (Schaedler et al. 2011) by using a sequence of several processing techniques in order to fabricate ultralight metallic microlattice materials (Schaedler and Carter 2016). There is still a long way to go for the industry to actually apply architectured materials in product manufacturing.

Architectured materials lie between the microscale and the macroscale. This class of materials involves geometrically engineered distributions of microstructural phases at a scale comparable to the scale of the component (Ashby and Bréchet 2003; Bouaziz et al. 2008; Bréchet and Embury 2013), thus calling for enriched models of continuum mechanics in order to determine the effective properties of materials (Geers and Yvonnet 2016; Matouš et al. 2017), e.g. generalised continua theories, in order to describe the behaviour of architectured materials, such as straingradient elasticity (Auffray et al. 2015), and strain-gradient plasticity. This topic has been especially fruitful these last few years in the mechanics of materials community (Lebée and Sab 2012; Trinh et al. 2012; Chen et al. 2014; Auffray et al. 2015; Placidi and El Dhaba 2015; Rosi and Auffray 2016; Andreaus et al. 2016; Placidi et al. 2017; dell'Isola et al. 2017); this results in the availability of versatile models able to describe the various situations encountered with architectured materials. Given mature processing techniques, architectured materials are promised to a bright future in industrial applications due to their enticing customisable specific properties and the opportunity of multifunctionality.

When considering actual applications, one engineering challenge is to predict the effective properties of such materials; computational homogenisation using finite element analysis is a powerful tool to do so. Homogenised behaviour of architectured materials can thus be used in large structural computations, hence enabling the dissemination of architectured materials in the industry. Furthermore, computational 
homogenisation is the basis for computational topology optimisation (Allaire 2002; Bendsøe and Sigmund 2004; Guest and Prévost 2006; Challis et al. 2008; Xu et al. 2016; Vicente et al. 2016; Xu et al. 2016; Salonitis et al. 2017; Asadpoure et al. 2017; Khakalo and Niiranen 2017; Wang et al. 2017) which will give rise to the next generation of architectured materials as it can already be seen in the works of (Laszczyk et al. 2009; Andreassen et al. 2014; Körner and Liebold-Ribeiro 2015; Hopkins et al. 2016; Kotani and Ikeda 2016; Ghaedizadeh et al. 2016; Ren et al. 2016; Liu et al. 2016; Dalaq et al. 2016).

Materials science comes from the following fact: microstructural heterogeneities play a critical role in the macroscopic behaviour of a material (Besson et al. 2010; Bornert et al. 2001; Jeulin and Ostoja-Starzewski 2001; François et al. 2012; Torquato 2001; Ostoja-Starzewski 2008). Constitutive modelling, thanks to an interaction between experiments and simulation, is usually able to describe the response of most materials in use. Such phenomenological models, including little to no information about the microstructure, cannot necessarily account for local fluctuation of properties. In that case, the material is considered as a homogeneous medium. Studying the behaviour of heterogeneous materials involves developing enriched models including morphological information about the microstructure (Smith and Torquato 1988; Yeong and Torquato 1998; Torquato et al. 1998; Decker et al. 1998; Jeulin 2000; Kanit et al. 2006; Peyrega et al. 2011; Jean et al. 2011; Escoda et al. 2015). These models should be robust enough to predict effective properties depending on statistical data (volume fraction, $n$-point correlation function, etc.) and the physical nature of each phase or constituent. As a matter of fact, advanced models are often restricted to a limited variety of materials. Although isotropic and anisotropic polycrystalline metals, for instance, have been extensively studied by the means of both analytical and computational tools (Cailletaud et al. 2003; Kanit et al. 2003; Madi et al. 2007; Berdin et al. 2013; Fritzen et al. 2013; Hor et al. 2014; Kowalski et al. 2016; Amodeo et al. 2016; Schindler et al. 2017), architectured materials bring up new challenges regarding the determination of effective properties.

The development of architectured materials is related to the availability of appropriate computational tools for both design and modelling, but also for computerised manufacturing as for the various additive manufacturing techniques considered to produce architectured materials.

\section{Computation for Design, Modelling, and Manufacturing}

The merit of additive manufacturing is often summarised as its ability to produce shapes that result from a topology optimisation process. Topology optimisation aims at attaining the most efficient structure for a given set of requirements. It is a longstanding topic of research and development for engineers that can be traced back to the seminal work of (Michell 1904) on frame structures one century ago, or even 30 
years earlier with (Lévy 1874), who gave the first proof for determinacy in statics for single-load trusses. The topic of optimisation has been active ever since. Nowadays, optimality in terms of industrial design is becoming more and more critical due to scarcity of material resources and the need for lightweight structures.

This technique has become well-established in the field of structural mechanics, especially when associated with FE simulation. Classical methods (Bendsøe and Kikuchi 1988; Rozvany 1995; Duysinx and Bendsøe 1998), such as SIMP (Bendsøe and Sigmund 2004) (Solid Isotropic Material with Penalisation) rely on node-based values to evaluate and optimise the geometry, i.e. the number of design variables is equal to the number of elements available in the model at initialisation. Then, the optimisation procedure consists in determining at each element if it should either stay a material element or become a void element, i.e. be removed. This technique has been applied to different scales: for instance with regards to the design of efficient building structures (Cui et al. 2003), or as a tool for designing micro- and nanoarchitectured materials (Zhou and Li 2008).

Most computational approaches for topology optimisation used in engineering are gradient-based, they are also known as local approaches. In recent years, so-called global approaches emerged, and are currently subject to epistemological controversy in the optimisation community due to the lack of proof for global convergence, as well as inefficiency in comparison with classical gradient methods (Sigmund 2011; Le Riche and Haftka 2012). Although the fact that being based on heuristics has been held against global approaches in structural mechanics, heuristics itself should not be considered a shortcoming but rather an epistemological hypothesis.

The computational framework being developed at PIMM rely on a global topologyoptimisation approach making use of cellular automata, as well as FE for evaluating of the cost function, which has to be minimised for given constraints (Bendsøe and Sigmund 2004). This evaluation step is straightforward since it consists in performing a FE computation on the generated model using predefined local constitutive behaviours, and averaging the response of the structure, to a given set of boundary conditions and applied loads, by the computational homogenisation method (Dirrenberger et al. 2011, 2012, 2013, 2014). The topology optimisation step is somewhat more difficult as choices have to be made with regards to the many approaches available and the type of problem being dealt with. Several reviews are available on this topic, see for instance (Bendsøe and Sigmund 2004; Rozvany 2009; Eschenauer and Olhoff 2001). Most developments in topology optimisation dealt with the efficiency of structures, i.e. minimising the mass of materials while optimising the elastic stiffness of a structure under a given load, which means choosing between void and matter for any given point in the design space, either continuous (Allaire 2002) or discrete (Bendsøe and Sigmund 2004).

Architecturation patterns can be either continuous, discrete, periodic or random, therefore cellular automata (CA) seem like natural candidates for generating them. CA correspond to an evolving structure based on a regular lattice, they are characterised by 5 properties: lattice geometry and dimensionality, cellular neighbourhood, cell state, local rule of transition, and boundary conditions. CA have already been used for topological optimisation, but not for solving pattern-type problems (Hajela 
and Kim 2001; Missoum et al. 2005; Hopman and Leamy 2010). An alternative method, the hybrid cellular automata (HCA) method, was proposed by (Tovar et al. 2004) by taking the best of both CA and SIMP. This method has been developed thoroughly for structural optimisation (Tovar et al. 2007). A critical improvement to the CA approach was the implementation of multigrid methods in order to accelerate the convergence during optimisation (Kim et al. 2004; Zakhama et al. 2009). The development of genetic algorithms in structural optimisation is known as evolutionary structural optimisation (ESO). It was first proposed by (Xie and Steven 1993; Chu et al. 1996) in the early 1990s, but suffered from various drawbacks (lack of convergence, mesh-dependency) which were partially overcome by the bi-directional evolutionary structural optimisation (BESO) approach developed by the same team a decade later (Huang and Xie 2007). Other developments have been undertaken regarding genetic algorithms, e.g. in terms of multi-criterion optimisation (Canyurt and Hajela 2010).

Therefore, a framework based on CA with a local rule of transition using the BESO approach, along with multigrid implementation appears like an appropriate option to design architectured materials, especially by the ability of such framework to deal with multiple scales of topology optimisation. In order to be fully efficient, the multiscale optimisation scheme must comply with optimising multiple anisotropic materials with nonlinear elastoplastic behaviour, which will yield nonlinearities in structural response of the architectured materials for various sets of requirements/cases of application, in terms of ductile fracture or fatigue properties (Torabian et al. 2016a, b, 2017a, b).

Generating and modelling shapes for additive manufacturing follows specific rules, coming from both processing constraints, e.g. layer thickness, product dimensions, etc., and the functional properties of the produced part, e.g. mechanical strength, thermal conductivity, etc. An usual and straightforward method for generating an additive manufacturing building path is to use a 3D-to-2D slicing software. It consists in slicing the 3D shape, i.e. computer-aided design (CAD) file, of an object into flat thin layers of constant thickness which can be layered one up onto the other, i.e. computer-aided manufacturing (CAM) file. This results in a cantilever-method strategy. Each layer is then made of a contour line, as well as a filling pattern such as a honeycomb structure or a space-filling curve (Peano curve, Hilbert curve, etc.); the filling density can be adjusted for given requirements. This method is well-established for small-scale additive manufacturing.

\section{Development of the Large-Scale Additive Manufacturing}

The industrial applications of small-scale additive manufacturing in production (in opposition to prototyping) concern either geometrically complex products in high value-adding sectors (biomedical, sports, aerospace) and/or parts made of costly materials, typically alloys which include Titanium, Nickel and/or Chrome in their 
composition. This type of additive manufacturing is usually powder-based, which is intrinsically costly, but enables very good spatial accuracy and microstructural control. Technologies such as direct metal laser sintering (DMLS), selective laser sintering (SLS), electron beam melting (EBM) or direct metal deposition (DMD) are taking off in high-end industries due to its cost-saving possibilities both in terms of reducing the number manufacturing steps and the amount of materials used (Gutowski et al. 2009; Allwood et al. 2011; Yoon et al. 2014; Baumers et al. 2016; Ford and Despeisse 2016).

The DEMOCRITE project (2014-2015, funded by HESAM Université) aimed at transposing such possibilities within an architectural context, i.e. developing largescale additive manufacturing with the same level of material performance than conventional processing methods and comparable accuracy as DMLS, i.e. a spatial resolution circa $0.1 \%$ of the building size, about $1 \mathrm{~mm}$ for a metre-wide printer. Our group at the PIMM lab explored the potential applications of large-scale additive manufacturing techniques to civil engineering structures. Thanks to this large-scale processing technique, one could apply the concept of architectured materials within an architectural context; multifunctional properties can be achieved for structural elements, by optimising geometry and material composition, as it was done in Gosselin et al. (2016), for an enhanced thermal insulation case study regarding a structural wall element produced by large-scale additive manufacturing. An example of topology optimisation based on the SIMP approach, performed during the DEMOCRITE project is given in Fig. 4.1. The initial optimisation results (Fig. 4.1a) were adapted and refined in order to fit the additive manufacturing constraints as well as the architectural scenario. The rendering shown on Fig. $4.1 \mathrm{~b}$ actually includes the visible layers of printed concrete resulting from the building process.

Based upon an understanding of the limitations identified in previous projects present in the literature, the DEMOCRITE project dealt with the large-scale additive
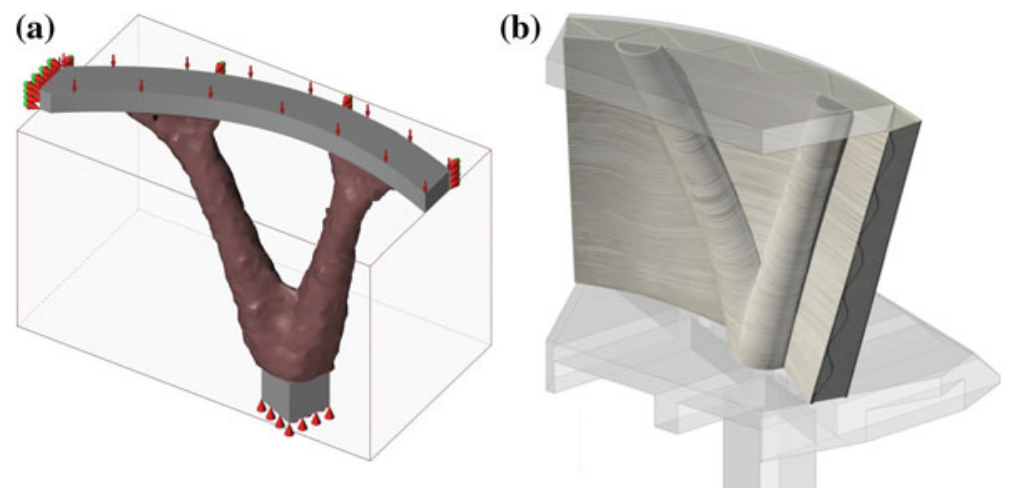

Fig. 4.1 An example of implementation of topology optimisation in the DEMOCRITE project: a Boundary conditions and results for the structural optimisation problem; $\mathbf{b}$ Rendering of the actual multifunctional wall including both the structural and thermal insulation parts 
manufacturing of selective deposition for ultra-high performance concrete (UHPC) (Duballet et al. 2015). The 3D printing process involved is based on a Fused Deposition Modelling-like technique, in the sense that a material is deposited layer-by-layer through an extrusion printhead. The project also explored the possibilities offered by $\mathrm{CAD}$ and optimisation, and their integration within the product design process in the case of large-scale additive manufacturing. Thus, the introduced technology succeeded in solving many of the problems that could be found in the literature. Most notably, the process enabled the production of 3D large-scale complex geometries, without the use of temporary supports, as opposed to $2.5 \mathrm{D}$ examples found in the literature for concrete 3D printing (Khoshnevis 2004; Buswell et al. 2007; Cesaretti et al. 2014).

According to Gosselin et al. (2016), the concept of freeform commonly used in the literature is not adequate nor sufficient for describing concrete $3 \mathrm{D}$ printing. For a given printing process and automation complexity, one can attain specific types of topologies within a given time-frame and performance criterion for the material and/or structure to be built. Design conditions for large-scale additive manufacturing depend on many other parameters than just the properties of extruded cementitious materials; parameters such as the printing spatial resolution, overall size of parts to be printed, the environment, the presence of assembling steps, etc. A tentative classification of such relationships between geometrical complexity, processing, and design is proposed in Duballet et al. (2017). The cantilever strategy, which is characteristic of small-scale additive manufacturing, is not appropriate for large-scale printing since it does not take into account the processing constraints and their impact on the performance of the printed structure. The building path should be adapted and optimized based on simulation results in order to take into account constraints and to exhibit more robustness for complex geometries.

The processing constraints depend mostly on the fresh material properties in its viscous state, as well as early-age behaviour, in interaction with the building strategy and the stiffness of the structure being built. On the other hand, functional requirements will depend on the properties of the hardened material, its durability (Lecampion et al. 2011), as well as the structural geometry for effective stiffness, and other functional properties such as thermal and sound insulation. See Gosselin et al. (2016) for a geometrically induced thermal insulation case study. Both types of constraints have to be considered at the design stage.

Printing path generation is a critical step during the design phase. There are two main approaches to tool-path generation in the context of 3D printing: (1) 3D-to2D slicing, which is by far the most common method adopted, yields planar layers of equal thickness built on top of each other. This approach is not optimal from a design and structural viewpoint as it will induce cantilevers when two consecutive layers have different sizes and limit the attainable geometries; (2) the tangential continuity method, which has been introduced in Gosselin et al. (2016) in order to optimise the structure being built by creating layers of varying thickness. These layers exhibit a maximised surface area of contact between each other, hence stabilising the overall structure. Moreover, this method is actually exploiting the possibilities 


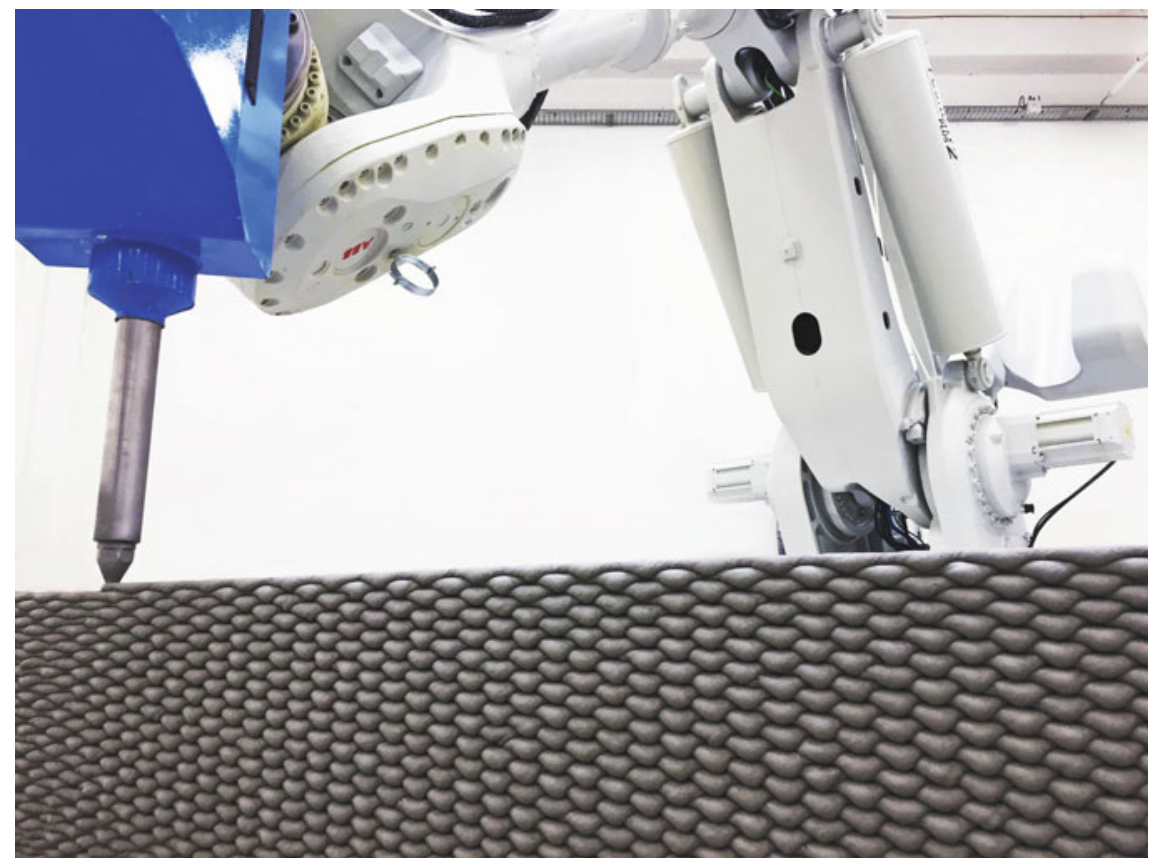

Fig. 4.2 The stand-alone concrete additive manufacturing process developed during the DEMOCRITE project, currently being implemented commercially by XtreeE

of the process in terms of printing speed and flow for generating variations in the layer thickness. Capitalising on the relative success of the DEMOCRITE project, a spin-off company, XtreeE, ${ }^{2}$ was created in order to develop and commercialise the $3 \mathrm{D}$ printing technology introduced. The large-scale robotic additive manufacturing process for concrete presented in Fig. 4.2 was developed during the DEMOCRITE project before being applied within the construction industry by XtreeE.

Figure 4.3 shows a 3D-printed 4 metre-high post supporting the playground roof of a school in Aix-en-Provence, France, produced by XtreeE. The structure was made of two parts: the 3D-printed envelope, used as a lost formwork, and the core, made of conventional cast concrete. The total printing time was $15 \mathrm{~h}$ and $30 \mathrm{~min}$.

A driving force for additive manufacturing is its ability to produce more complex $3 \mathrm{D}$ shapes in comparison to casting or subtractive processes. This complexity allows to design optimal structures based on topology optimisation techniques. One of the main current challenges is to modify optimisation algorithms in order to account for the additive manufacturing constraints, especially with regards to the processing parameters and structural stability while printing. A possible answer to these challenges would be to consider the multiphysics phenomenon aspect of 3D printing, which involves the elastic stability of the overall structure being built, the kinetics 

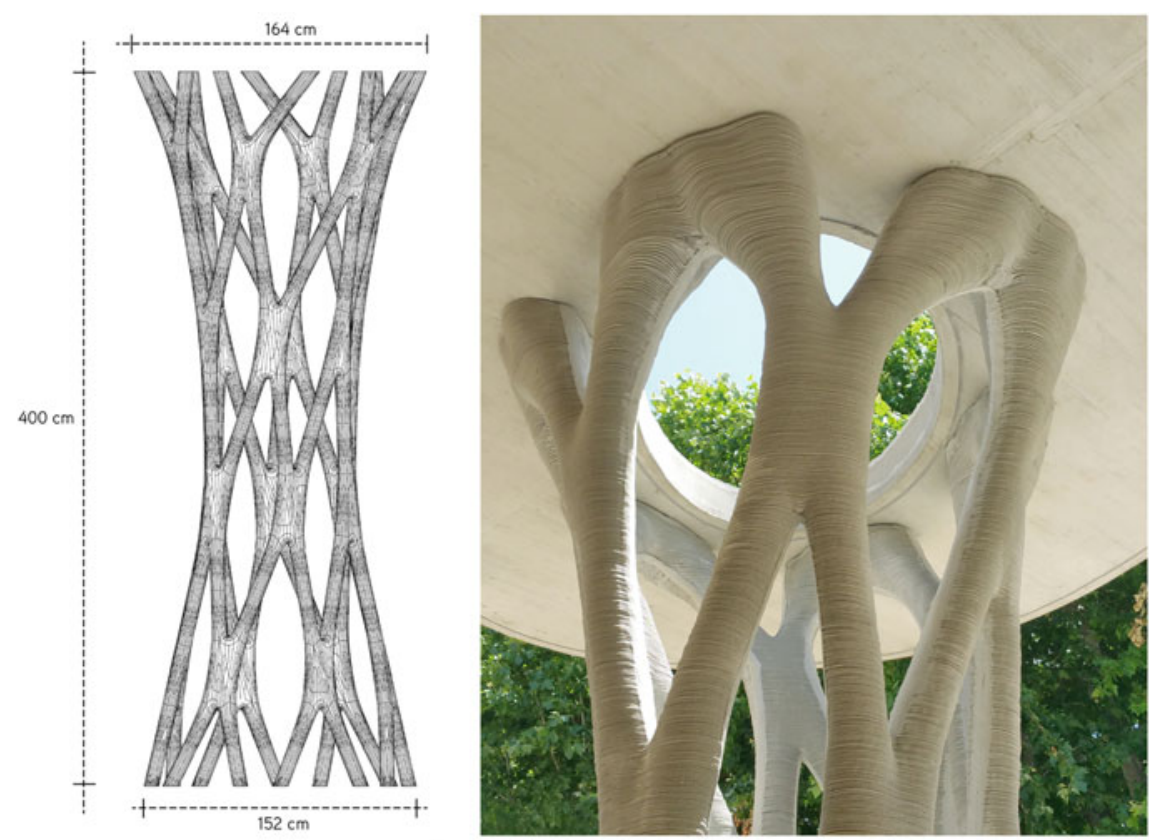

Fig. 4.3 Close-up view of a 4 metre-high post in Aix-en-Provence, France. Source www.xtreee. com

of hydration, the evolving viscoplasticity of fresh cement, the evolution of temperature within the printing environment, etc. As a matter of fact, all these physical problems, with multiple time and space scales, can be modelled on their own, but coupling them generates complexity and uncertainty regarding the process of $3 \mathrm{D}$ printing. Therefore, efforts should be concentrated on understanding and modelling the printing process in its multiple physical aspects, only then optimisation will be fully integrated with the processing, which would virtually change the way $3 \mathrm{D}$ printed structures are conceived today. An attempt at multi-objective optimisation for thermal, mechanical and economical criteria, in the context of a hybrid largescale concrete 3D printing and assembling process, was proposed by Duballet et al. (2018). It consists in fabricating insulating blocks, which would be assembled by robots in order to form a layer of printing support for the mortar to be extruded; at the end, tie columns and ring beams will ensure the masonry confinement. This approach is rather new in comparison with most examples of large-scale concrete 3D printing available (Labonnote et al. 2016; Duballet et al. 2017). Indeed, the future of large-scale additive manufacturing in architecture and construction might reside in smarter, more parsimonious use of 3D printing on specific parts of the printed object, where it is the most pertinent in order to take advantage of both the material properties and morphology of the structure being built. 


\section{Conclusions and Perspectives}

An overview was given regarding the concept of architectured materials in general, i.e. highlighting the importance of geometry at multiple scales, as well as the computational tools associated with their development. In fact, this development is made possible by the computerisation of both the designing step, and robotisation of the manufacturing step. This automation of the process theoretically allows for a higher accuracy and infinite customisation of materials and structures according to a given set of requirements. In this context, the top-down approach of architectured materials, i.e. going from the application down to the design of materials, becomes generalisable, hence yielding new opportunities for the built environment sector, e.g. in architectural design, structural engineers' calculations, or the logistics of a construction site, if building information modelling (BIM) is integrated. From an application viewpoint, one of the most critical point is indeed to be able to incorporate robotic actions within the BIM model.

Acknowledgements This work is part of the DEMOCRITE (Large-scale additive manufacturing platform) Project PNM-14-SYNG-0002-01, as well as the SCOLASTIC (Systematic Computational Optimisation and Local Laser Processing for Steel-Based Architectured Materials) Project ANR 16-CE08-0009. The author would like to gratefully acknowledge ANR (Agence Nationale de la Recherche), and heSam Université for financial support through its Paris Nouveaux Mondes program.

\section{References}

Ajdari A, Jahromi BH, Papadopoulos J, Nayeb-Hashemi H, Vaziri A (2012) Hierarchical honeycombs with tailorable properties. Int J Solids Struct 49(11-12):1413-1419

Allaire G (2002) Shape optimization by the homogenization method. Springer

Allwood JM, Ashby MF, Gutowski TG, Worrell E (2011) Material efficiency: a white paper. Resour Conserv Recycl 55(3):362-381

Amodeo J, Dancette S, Delannay L (2016) Atomistically-informed crystal plasticity in MgO polycrystals under pressure. Int J Plast 82:177-191

Andreassen E, Lazarov B, Sigmund O (2014) Design of manufacturable 3D extremal elastic microstructure. Mech Mater 69(1):1-10

Andreaus U, dell'Isola F, Giorgio I, Placidi L, Lekszycki T, Rizzi NL (2016) Numerical simulations of classical problems in two-dimensional (non) linear second gradient elasticity. Int J Eng Sci 108:34-50

Asadpoure A, Tootkaboni M, Valdevit L (2017) Topology optimization of multiphase architected materials for energy dissipation. Comput Methods Appl Mech Eng 325:314-329

Ashby MF, Bréchet Y (2003) Designing hybrid materials. Acta Mater 51:5801-5821

Auffray N, Dirrenberger J, Rosi G (2015) A complete description of bi-dimensional anisotropic strain-gradient elasticity. Int J Solids Struct 69-70:195-210

Baumers M, Dickens P, Tuck C, Hague R (2016) The cost of additive manufacturing: machine productivity, economies of scale and technology-push. Technological Forecasting \& Social Change

Bendsøe M, Kikuchi N (1988) Generating optimal topologies in structural design using a homogenization method. Comput Methods Appl Mech Eng

Bendsøe M, Sigmund O (2004) Topology optimization. Springer 
Berdin C, Yao ZY, Pascal S (2013) Internal stresses in polycrystalline zirconia: microstructure effects. Comput Mater Sci 70:140-144

Bertoldi K, Reis P, Willshaw S, Mullin T (2010) Negative Poisson's ratio behavior induced by an elastic instability. Adv Mater 22(3):361-366

Besson J, Cailletaud G, Chaboche J-L, Forest S, Blétry M (2010) Non-linear mechanics of materials, vol 167. Solid Mechanics and Its Applications. Springer, Heidelberg

Bironeau A, Dirrenberger J, Sollogoub C, Miquelard-Garnier G, Roland S (2016) Evaluation of morphological representative sample sizes for nanolayered polymer blends. J Microsc 264(1):4858

Bornert M, Bretheau T, Gilormini P (2001) Homogénéisation en mécanique des matériaux, Tome 1: Matériaux aléatoires élastiques et milieux périodiques. Hermès

Bouaziz O, Bréchet Y, Embury JD (2008) Heterogeneous and architectured materials: a possible strategy for design of structural materials. Adv Eng Mater 10(1-2):24-36. https://doi.org/10. 1002/adem.200700289

Bouaziz O, Masse JP, Allain S, Orgéas L, Latil P (2013) Compression of crumpled aluminum thin foils and comparison with other cellular materials. Mater Sci Eng A: Structural Materials: Properties, Microstructure and Processing 570:1-7

Bréchet Y, Embury JD (2013) Architectured materials: expanding materials space. Scripta Mater 68(1):1-3

Brothers AH, Dunand DC (2006) Density-graded cellular aluminum. Adv Eng Mater 8(9):805-809

Buswell R, Soar R, Gibb A, Thorpe A (2007) Freeform construction: mega-scale rapid manufacturing for construction. Automation Construction 16:224-231

Cailletaud G, Forest S, Jeulin D, Feyel F, Galliet I, Mounoury V, Quilici S (2003) Some elements of microstructural mechanics. Comput Mater Sci 27:351-374

Canyurt OE, Hajela P (2010) Cellular genetic algorithm technique for the multicriterion design optimization. Struct Multidiscip Optim 40:201-214

Caty O, Maire E, Bouchet R (2008) Fatigue of metal hollow spheres structures. Adv Eng Mater 10(3):179-184

Cesaretti G, Dini E, Kestelier XD, Colla V, Pambaguian L (2014) Building components for an outpost on the Lunar soil by means of a novel 3D printing technology. Acta Astronaut 93:430 450

Challis VJ, Roberts AP, Wilkins AH (2008) Design of three dimensional isotropic microstructures for maximized stiffness and conductivity. Int J Solids Struct 45:4130-4146

Chéhab B, Zurob H, Embury D, Bouaziz O, Bréchet Y (2009) Compositionally graded steels: a strategy for materials development. Adv Eng Mater 11(12):992-999

Chen Y, Liu XN, Hu GK, Sun QP, Zheng QS (2014) Micropolar continuum modeling of bidimensional tetrachiral lattices. Proc R Soc A Math Phys Eng Sci 470(2165):20130734

Chu DN, Xie YM, Hira A, Steven GP (1996) Evolutionary structural optimization for problems with stiffness constraints. Finite Elem Anal Des 21(4):239-251

Courtois L, Maire E, Perez M, Rodney D, Bouaziz O, Bréchet Y (2012) Mechanical properties of monofilament entangled materials. Adv Eng Mater 14(12):1128-1133

Cui C, Ohmori H, Sasaki M (2003) Computational morphogenesis of 3D structures by extended ESO method. J Int Assoc Shell Spatial Struct 44(1):51-61

Dalaq AS, Abueidda DW, Al-Rub RKA, Jasiuk IM (2016) Finite element prediction of effective elastic properties of interpenetrating phase composites with architectured 3D sheet reinforcements. Int J Solids Struct 83:169-182

Decker L, Jeulin D, Tovena I (1998) 3D morphological analysis of the connectivity of a porous medium. Acta Stereologica 17(1):107-112

dell'Isola F, Della Corte A, Giorgio I (2017) Higher-gradient continua: the legacy of Piola, Mindlin, Sedov and Toupin and some future research perspectives. Math Mech Solids 22(4):852-872

Deshpande VS, Fleck NA (2000) Isotropic constitutive models for metallic foams. J Mech Phys Solids 48:1253-1283 
Deshpande VS, Fleck NA, Ashby MF (2001) Effective properties of the octet-truss lattice material. J Mech Phys Solids 49(8):1747-1769

Dirrenberger J (2012) Effective properties of architectured materials. Ph.D. Thesis, MINESParisTech, Paris, Dec 2012

Dirrenberger, J.: From architectured materials to the development of large-scale additive manufacturing. SPOOL 4(1):13-16 (2017). https://journals.library.tudelft.nl/index.php/spool/article/ view/1910

Dirrenberger J, Forest S, Jeulin D (2013) Effective elastic properties of auxetic microstructures: anisotropy and structural applications. Int J Mech Mater Des 9(1):21-33. https://doi.org/10.1007/ s10999-012-9192-8

Dirrenberger J, Forest S, Jeulin D (2012) Elastoplasticity of auxetic materials. Comput Mater Sci 64:57-61. https://doi.org/10.1016/j.commatsci.2012.03.036

Dirrenberger J, Forest S, Jeulin D (2014) Towards gigantic RVE sizes for stochastic fibrous networks. Int J Solids Struct 51(2):359-376. https://doi.org/10.1016/j.ijsolstr.2013.10.011

Dirrenberger J, Forest S, Jeulin D, Colin C (2011) Homogenization of periodic auxetic materials. Procedia Engineering 10. In: 11th international conference on the mechanical behavior of materials (ICM11), 1847-1852. https://doi.org/10.1016/j.proeng.2011.04.307

Djumas L, Molotnikov A, Simon GP, Estrin Y (2016) Enhanced mechanical performance of bioinspired hybrid structures utilising topological interlocking geometry. Sci Rep 6:26706

Duballet R, Baverel O, Dirrenberger J (2017) Classification of building systems for concrete 3D printing. Autom Constr 83:247-258

Duballet R, Baverel O, Dirrenberger J (2018) Design of space truss based insulating walls for robotic fabrication in concrete. In: Rycke KD, Gengnagel C, Baverel O, Burry J, Mueller C, Nguyen MM, Rahm P, Thomsen MR (eds) Humanizing digital reality, Chap. 39, pp. 453-461. Springer. https:// doi.org/10.1007/978-981-10-6611-5_39

Duballet R, Gosselin C, Roux P (2016) Additive manufacturing and multi-objective optimization of graded polystyrene aggregate concrete structures. In: Thomsen M, Tamke M, Gengnagel C, Faircloth B, Scheurer F (eds) Modelling behaviour- design modelling symposium 2015, Chap. Additive manufacturing and multi-objective optimization of graded polystyrene aggregate concrete structures

Duysinx P, Bendsøe MP (1998) Topology optimization of continuum structures with local stress constraints. Int J Numer Meth Eng 43(8):1453-1478

Embury D, Bouaziz O (2010) Steel-based composites: driving forces and classifications. Annu Rev Mater Res 40:213-241

Erk KA, Dunand DC, Shull KR (2008) Titanium with controllable pore fractions by thermoreversible gelcasting of TiH2. Acta Mater 56(18):5147-5157

Eschenauer HA, Olhoff N (2001) Topology optimization of continuum structures: a review. Appl Mech Rev 54(4):331-390

Escoda J, Jeulin D, Willot F, Toulemonde C (2015) Three-dimensional morphological modeling of concrete using multiscale Poisson polyhedra. J Microsc 258(1):31-48

Fallet A, Lhuissier P, Salvo L, Bréchet Y (2008) Mechanical behaviour of metallic hollow spheres foam. Adv Eng Mater 10(9):858-862

Fleck NA, Deshpande VS, Ashby MF (2010) Micro-architectured materials: past, present and future. Proc R Soc A Math Phys Eng Sci 466(2121):2495-2516

Ford S, Despeisse M (2016) Additive manufacturing and sustainability: an exploratory study of the advantages and challenges. J Clean Prod 137:1573-1587

François D, Pineau A, Zaoui A (2012) Mechanical behaviour of materials, volume 1: microand macroscopic constitutive behaviour, vol. 180. Solid mechanics and its applications. Springer

Freeman AJ (2002) Materials by design and the exciting role of quantum computation/simulation. J Comput Appl Math 149(1):27-56

Fritzen F, Forest S, Kondo D, Böhlke T (2013) Computational homogenization of porous materials of Green type. Comput Mech 52(1):121-134 
Geers MGD, Yvonnet J (2016) Multiscale modeling of microstructure-property relations. MRS Bull 41(8):610-616

Ghaedizadeh A, Shen J, Ren X, Xie YM (2016) Tuning the performance of metallic auxetic metamaterials by using buckling and plasticity. Materials 9(54):1-17

Gosselin C, Duballet R, Roux P, Gaudillière N, Dirrenberger J, Morel P (2016) Large-scale 3D printing of ultra-high performance concrete- a new processing route for architects and builders. Mater Des 100:102-109

Guest JK, Prévost JH (2006) Optimizing multifunctional materials: design of microstructures for maximized stiffness and fluid permeability. Int J Solids Struct

Gutowski TG, Branham MS, Dahmus JB, Jones AJ, Thiriez A, Sekulic DP (2009) Thermodynamic analysis of resources used in manufacturing processes. Environ Sci Technol 43(5):1584-1590

Hajela P, Kim B (2001) On the use of energy minimization for CA based analysis in elasticity. Struct Multidiscip Optim 23:24-33

Hopkins JB, Shaw LA, Weisgraber TH, Farquar GR, Harvey CD, Spadaccini CM (2016) Design of nonperiodic microarchitectured materials that achieve graded thermal expansions. J Mech Robot 8(5):051010

Hopman RK, Leamy MJ (2010) Triangular cellular automata for computing two-dimensional elastodynamic response on arbitrary domains. J Appl Mech 78(2):021020

Hor A, Saintier N, Robert C, Palin-Luc T, Morel F (2014) Statistical assessment of multiaxial HCF criteria at the grain scale. Int J Fatigue 67:151-158

Huang X, Xie YM (2007) Convergent and mesh-independent solutions for bi-directional evolutionary structural optimization method. Finite Elem Anal Des 43(14):1039-1049

Hummel RE (2004) Understanding materials science, 2 edn. Springer-Verlag, New York

Jean A, Jeulin D, Forest S, Cantournet S, N'Guyen F (2011) A multiscale microstructure model of carbon black distribution in rubber. J Microsc 241(3):243-260

Jeulin D (2000) Random texture models for material structures. Stat Comput 10(2):121-132

Jeulin D, Ostoja-Starzewski M (2001) Mechanics of random and multiscale microstructures. CISM courses. Springer, Heidelberg

Kanit T, Forest S, Galliet I, Mounoury V, Jeulin D (2003) Determination of the size of the representative volume element for random composites: statistical and numerical approach. Int J Solids Struct 40:3647-3679

Kanit T, N'Guyen F, Forest S, Jeulin D, Reed M, Singleton S (2006) Apparent and effective physical properties of heterogeneous materials: representativity of samples of two materials from food industry. Comput Methods Appl Mech Eng 195:3960-3982

Khakalo S, Niiranen J (2017) Isogeometric analysis of higher-order gradient elasticity by user elements of a commercial finite element software. Comput Aided Des 82:154-169

Khoshnevis B (2004) Automated construction by contour crafting- related robotics and information technologies. Autom Construct 13:5-19

Kim S, Abdalla MM, Gürdal Z, Jones M (2004) Multigrid accelerated cellular automata for structural design optimization: A 1-D implementation. In: 45th AIAA/ASME/ASCE/AHS/ASC structures, structural dynamics and materials conference, Palm Springs, California

Kolopp A, Rivallant S, Bouvet C (2013) Experimental study of sandwich structures as armour against medium-velocity impacts. Int J Impact Eng 61:24-35

Körner C, Liebold-Ribeiro Y (2015) A systematic approach to identify cellular auxetic materials. Smart Mater Struct 24(2):025013

Kotani M, Ikeda S (2016) Materials inspired by mathematics. Sci Technol Adv Mater 17(1):253-259

Kowalski N, Delannay L, Yan P, Remacle JF (2016) Finite element modeling of periodic polycrystalline aggregates with intergranular cracks. Int J Solids Struct 90:60-68

Labonnote N, Ronnquist A, Manum B, Rüther P (2016) Additive construction: state-of-the-art, challenges and opportunities. Autom Construct 72:347-366

Laszczyk L, Dendievel R, Bouaziz O, Bréchet Y, Parry G (2009) Design of architectured sandwich core materials using topological optimization methods. In: symposium LL-architectured multifunctional materials, vol. 1188, MRS Proceedings 
Le Riche R, Haftka RT (2012) On global optimization articles in SMO. Struct Multidiscip Optim 46:627-629

Lebée A, Sab K (2012) Homogenization of thick periodic plates: application of the bending-gradient plate theory to a folded core sandwich panel. Int J Solids Struct 49(19-20):2778-2792

Lecampion B, Vanzo J, Ulm F-J, Huet B, Germay C, Khalfallah I, Dirrenberger J (2011) Evolution of portland cement mechanical properties exposed to $\mathrm{CO} 2$-rich fluids: investigation at different scales. In: MPPS 2011, symposium on mechanics and physics of porous solids : a tribute to Pr. Olivier Coussy

Lévy M (1874) La statique graphique et ses applications aux constructions. Gauthier-Villars, Paris

Lewandowski M, Amiot M, Perwuelz A (2012) Development and characterization of 3D nonwoven composites. In: Boudenne A (ed) Materials science forum. Polymer composite materials: From Macro, Micro to Nanoscale, vol 714, pp 131-137

Liu J, Gu T, Shan S, Kang SH, Weaver JC, Bertoldi K (2016) Harnessing buckling to design architected materials that exhibit effective negative swelling. Adv Mater 28(31):6619-6624

Madi K, Forest S, Boussuge M, Gailliègue S, Lataste E, Buffière J-Y, Bernard D, Jeulin D (2007) Finite element simulations of the deformation of fused-cast refractories based on X-ray computed tomography. Comput Mater Sci 39:224-229

Matouš K, Geers MGD, Kouznetsova VG, Gillman A (2017) A review of predictive nonlinear theories for multiscale modeling of heterogeneous materials. J Comput Phys 330:192-220

Mezeix L, Bouvet C, Huez J, Poquillon D (2009) Mechanical behavior of entangled fibers and entangled cross-linked fibers during compression. J Mater Sci 44(14):3652-3661

Michell AGM (1904) The limit of economy of material in frame structures. Phil Mag 8(6):589-597

Mirkhalaf M, Khayer Dastjerdi A, Barthelat F (2014) Overcoming the brittleness of glass through bio-inspiration and micro-architecture. Nature Commun

Missoum S, Gürdal Z, Setoodeh S (2005) Study of a new local update scheme for cellular automata in structural design. Struct Multidiscip Optim 29:103-112

Olson GB (2001) Beyond discovery: design for a new material world. Calphad 25(2):175-190

Ostoja-Starzewski M (2008) Microstructural randomness and scaling in mechanics of materials. Mordern mechanics and mathematics. Chapman \& Hall/CRC

Peyrega C, Jeulin D, Delisée C, Malvestio J (2011) 3D morphological characterization of phonic insulation fibrous media. Adv Eng Mater 13(3):156-164

Placidi L, Barchiesi E, Della Corte A (2017) Identification of two-dimensional pantographic structures with a linear $\mathrm{d} 4$ orthotropic second gradient elastic model accounting for external bulk double forces. In: dell'Isola F, Sofonea M, Steigmann D (eds) Mathematical modelling in solid mechanics, Advanced structured materials, Chap 14, vol 69, pp 211-232. Springer, Singapore. https://doi.org/10.1007/978-981-10-3764-1_14

Placidi L, El Dhaba AR (2015) Semi-inverse method à la Saint-Venant for two-dimensional linear isotropic homogeneous second-gradient elasticity. Math Mech Solids 22(5):919-937

Rayneau-Kirkhope D, Mao Y, Farr R (2012) Ultralight fractal structures from hollow tubes. Phys Rev Lett 109(204301)

Ren X, Shen J, Ghaedizadeh A, Tian H, Xie YM (2016) A simple auxetic tubular structure with tuneable mechanical properties. Smart Mater Struct

Rosi G, Auffray N (2016) Anisotropic and dispersive wave propagation within strain-gradient framework. Wave Motion 63:120-134

Rozvany GIN (2009) A critical review of established methods in structural topology optimization. Struct Multidiscip Optim 37:217-237

Rozvany GIN, Bendsøe MP, Kirsch U (1995) Layout optimization of structures. Appl Mech Rev 48(2):41-119

Salonitis K, Chantzis D, Kappatos V (2017) A hybrid finite element analysis and evolutionary computation method for the design of lightweight lattice components with optimized strutdiameter. Int J Adv Manufact Technol 90(9-12):2689-2701

Schaedler TA, Carter WB (2016) Architected cellular materials. Ann Rev Mater Res 46:187-210 
Schaedler TA, Jacobsen AJ, Torrents A, Sorensen AE, Lian J, Greer JR, Valdevit L, Carter WB (2011) Ultralight metallic microlattices. Science 334(6058):962-965

Schindler S, Mergheim J, Zimmermann M, Aurich JC, Steinmann P (2017) Numerical homogenization of elastic and thermal material properties for metal matrix composites (MMC). Continuum Mech Thermodyn 29(1):51-75

Shim J, Shan S, Košmrlj A, Kang SH, Chen ER, Weaver JC, Bertoldi K (2013) Harnessing instabilities for design of soft reconfigurable auxetic/chiral materials. Soft Matter 9(34):8198-8202

Sigmund O (2011) On the usefulness of non-gradient approaches in topology optimization. Struct Multidiscip Optim 43:589-596

Smith P, Torquato S (1988) Computer simulation results for the two-point probability function of composite media. J Comput Phys 76(1):176-191

Steeves CA, Santos e Lucato SL, dos He M, Antinucci E, Hutchinson JW, Evans AG (2007) Concepts for structurally robust materials that combine low thermal expansion with high stiffness. J Mech Phys Solids 55:1803-1822

Stoychev G, Zakharchenko S, Turcaud S, Dunlop JWC, Ionov L (2012) Shape-programmed folding of stimuli-responsive polymer bilayers. ACS Nano 6(5):3925-3934

Torabian N, Favier V, Dirrenberger J, Adamski F, Ziaei-Rad S, Ranc N (2017) Correlation of the high and very high cycle fatigue response of ferrite based steels with strain ratetemperature conditions. Acta Mater 134:40-52

Torabian N, Favier V, Ziaei-Rad S, Adamski F, Dirrenberger J, Ranc N (2016) Self-heating measurements for a dual-phase steel under ultrasonic fatigue loading for stress amplitudes below the conventional fatigue limit. Proc Struct Integr 2:1191-1198

Torabian N, Favier V, Ziaei-Rad S, Dirrenberger J, Adamski F, Ranc N (2017) Calorimetric studies and self-heating measurements for a dual-phase steel under ultrasonic fatigue loading. In: Wei Z, Nikbin K, McKeighan P, Harlow D (eds) Fatigue and fracture test planning, test data acquisitions and analysis, vol STP1598, pp 81-93, ASTM (2017). https://doi.org/10.1520/STP159820160053

Torabian N, Favier V, Ziaei-Rad S, Dirrenberger J, Adamski F, Ranc N (2016) Thermal response of DP600 dual-phase steel under ultrasonic fatigue loading. Mater Sci Eng A Struct Mater Prop Microstruct Process 677:97-105

Torquato S (1998) Morphology and effective properties of disordered heterogeneous media. Int J Solids Struct 35(19):2385-2406

Torquato S (2001) Random heterogeneous materials. Springer

Tovar A, Niebur GL, Sen M, Renaud JE, Sanders B (2004) Bone structure adaptation as a cellular automaton optimization process. In: 45th AIAA/ASME/ASCE/AHS/ASC Structures, structural dynamics \& materials conference, Palm Springs, California

Tovar A, Patel NM, Kaushik AK, Renaud JE (2007) Optimality conditions of the hybrid cellular automata for structural optimization. AIAA J 45(3):673-683

Trinh DK, Jänicke R, Auffray N, Diebels S, Forest S (2012) Evaluation of generalized continuum substitution models for heterogeneous materials. Int J Multiscale Comput Eng 10(6):527-549

Turcaud S, Guiducci L, Fratzl P, Dunlop JWC, Bréchet Y (2011) An excursion into the design space of biomimetic architectured biphasic actuators. Int J Mater Res 102(6):607-612

Vicente WM, Zuo ZH, Pavanello R, Calixto TKL, Picelli R, Xie YM (2016) Concurrent topology optimization for minimizing frequency responses of two-level hierarchical structures. Comput Methods Appl Mech Eng 301:116-136

Wang ZP, Poh LH, Dirrenberger J, Zhu Y, Forest S (2017) Isogeometric shape optimization of smoothed petal auxetic structures via computational periodic homogenization. Comput Methods Appl Mech Eng 323:250-271

Weaver PM, Ashby MF (1996) The optimal selection of material and section-shape. J Eng Des 7(2):129-150

Xie YM, Steven GP (1993) A simple evolutionary procedure for structural optimization. Comput Struct 49:885-896 
Xu B, Huang X, Zhou SW, Xie YM (2016) Concurrent topological design of composite thermoelastic macrostructure and microstructure with multi-phase material for maximum stiffness. Compos Struct 150:84-102

Xu S, Shen J, Zhou S, Huang X, Xie YM (2016) Design of lattice structures with controlled anisotropy. Materials and Design

Yeong CLY, Torquato S (1998) Reconstructing random media. Phys Rev E

Yoon HS, Lee JY, Kim HS, Kim MS, Kim ES, Shin YJ, Chu WS, Ahn SH (2014) A comparison of energy consumption in bulk forming, subtractive, and additive processes: review and case study. Int J Precis Eng Manufact Green Technol 1(3):261-279

Zakhama R, Abdalla MM, Smaoui H, Gürdal Z (2009) Multigrid implementation of cellular automata for topology optimization of continuum structures. Comput Modeling Eng Sci 51(1):124

Zhou S, Li Q (2008) Design of graded two-phase microstructures for tailored elasticity gradients. J Mater Sci 43:5157-5167 